\title{
CORRESPONDENCE ON BASE ISOLATED STRUCTURES
}

Dr R. W. G. Blakeley ${ }^{(1)}$ answers several queries concerning the recommendations for the design of base isolated structures, published in the rine Bulletin (Vol. 12 No. 2 March, 1979).

Your letter was passed on to me by the Secretary of the New Zealand National Society for Earthquake Engineering. Thank you for your comments. I will attempt to answer your questions as follows:

1. "Is base isolation by rocking on foundations intended as a practical design procedure for routine design of buildings and their parts?"

Yes, provided the recommendations in Section 3.5 of our report are followed and the induced displacements are within acceptable limits. However, note that the type of structure our recommendations refer to are those tilting on a rigid base and not to buildings with isolated columns lifting under seismic response.

2. 'If so, what ' $S$ ' factor is to be used and are dampers necessary? Are there to be two alternatives, i.e. a low ' $S$ ' factor with dampers and a higher ' $S$ ' factor without dampers?"

our recommendation in Section 2.1.1 is that the Structural Type Factor, S, for base isolated structures be 0.7 . This is intended to include structures rocking on their foundations as discussed in Section 3.5. You have pointed out that this figure is much lower than the $S=1.4$ recommended by $\mathrm{P}$. W. Taylor and R. I. Williams in their paper "Foundations for Capacity Design Structures" Proceedings South Pacific Regional Conference on Earthquake Engineering, May 1979. However, there is probably an unfortunate clash of nomenclature involved. Taylor and Williams are referring to "rocking" as a matter of foundation compliance, for example with isolated columns "lifting" off the foundations and deformation of the soil under a significant proportion of the base area. On the other hand we are referring to "rocking" as a matter of tilting of a structure on a rigid base with a relatively small area in contact with the soil. We believe that the S factor of 1.4 nominated by Taylor and Williams includes an allowance for unknowns in behaviour which may be somewhat conservative.

Some "Rocking" structures, in the context of our recommendations, designed to date have effectively been based on an $S$ factor of less than 1, for example the South Rangitikei Rail Bridge piers and the "rocking" chimney constructed in Christchurch. This would appear to indicate a confidence in the general mechanism. It should be noted that an increase in the $S$ factor above what we have recommended would cause a proportional

(1) Special Projects Engineer, Head Office, Ministry of Works and Development. increase in the level of response at "lift-off", but would not have the same effect on the maximum rocking displacement.

Energy dissipating devices are not necessarily required in rocking structures. They may be needed to keep deflections within acceptable limits. This may be particularly so for tall slender structures, which have less damping through impact than squat structures.

3. "Is the "overcapacity factor" of 1.3 in clause 3.5.3.3 meant to be used with the load factor equations of clause 1.3.2:3, of NZS 4203 but for some actions only? What are the design steps to be taken, considering both the strength method, and capacity design, and concurrency effects? Is the superstructure to be "ductile" or "limited ductile" when using the factor 1.3 of clause $3 \cdot 5 \cdot 3.3$ of the Report?"

Yes, the factor of 1.3 is intended to be used with the load factor equations of NZS 4203. The factor of 1.3 is simply an overstrength factor comparable to that used in conventional capacity design, with the objective of ensuring elastic structural response of the rocking system under forces somewhat higher than the calculated base shear to initiate rocking.

As explained in the report, the value of 1. 3 may appear to be high but has been adopted to protect against higher mode effects and shockload accelerations occuring at impact. It is envisaged then that the super-structure will remain elastic. The reference to capacity reduction factors in the report was with regard to ensuring a margin of protection against shear failure, that is a satisfactory hierarchy of failure. It was considered that such a margin would be present because of the lower capacity reduction factor required by the concrete design code for shear than for flexure.

4. "Which elements require ductile detailing?"

As discussed in 3 above, the type of "tilting" structure to which these recommendations apply will usually take advantage of the limiting of peak lateral accelerations so that an elastic structural design may be adopted. Ductile detailing is not then required.

With regard to your comments on forwarding our recommendations to the Loadings Code Amendment Committee of SANZ, no formal approach has been made but we assume that the committee will give our recommendations due consideration in their review of NZS 4203.

and $M r$ R. L. Wizzioms (2) adds:

(2) Ministry of Works and Development, Hamilton. 
When considering our paper, "Foundations for Capacity Designed Structures", South Pacific Regional Conference on Earthquake Engineering, May 1979, Prof. Taylor and I recommended $S=1.4$ because we were considering the general case where dynamic studies had not been carried out. It was felt that this system was more desirable than shear walls not designed for ductility $(S=1.6)$ yet the amount of damping and whether the period shift is on the ascending or descending part of the response curve may not be accurately known. Deflections with rocking need to be carefully considered, particularly in buildings where damage to secondary elements, floor slabs, etc. can easily occur. The example in the paper "Seismic Response of Structures Free to Rock on their Foundations" by Priestley, Evison and Carr (N.Z. National Society for Earthquake Engineering Bulletin Vol. 11 No. 3 September 1978) an apparent $\mathrm{S}$ factor of roughly $\mathrm{S}+1.4$ was used yet the deflections at roof level came very close to the absolute limit of NZS $42031976 \mathrm{Cl}$. 3.8.3.2 of 0.01 times the height.

We therefore are recommending that values of not less than $\mathrm{S}=1.4$ be used unless all aspects of the behaviour have been fully investigated.

With regard to the rocking of the footing with and without ground compliance, we considered the general case where yielding of the soil may or may not occur. The area of contact in most cases is surprisingly low. It should be noted that only end columns of frames where there is a substantial weight transfer are axial loads likely to become the critical loading. This reserve of axial load carrying ability built into the design by the factors of safety for bearing and loading mean that the yielding will not spread to the full footing width and catastrophic failure under axial load will not occur during rocking.

Your suggested factor of overstrength of 1.3 for the superstructure above the maximum rocking force is probably not unreasonable to cover overstrength in the rocking mechanism and possible higher mode effects and should be incorporated in our procedure where applicable.

Acknowledgement: Dr. Blakeley and Mr Williams are thanked for permission to publish this correspondence.

John Leuchars (3) writes about his experience in checking the bearing system for the Koeburg Nuclear Power Station near Capetown, South Africa.

The 1800M Power Station was designed and built by a French consortium with the civil and structural work being carried out by Spie Batignoles. F. Jclivet and M. Richli. (see Reference 17 of the paper by Blakeley and others) were responsible for the bearing research and development work, and Ove Arup and Partners for checking the bearing design.

The bearing system consisted of a large number of multilayer neoprene/steel bearings with a bearium (lead impregnated bronze) top plate. This formed a friction couple with an upper plate of stainless steel cast into the underside of the slab forming the nuclear island. The system was designed to act in an elastic manner until an acceleration greater than the friction cipacity (approximately 0.2) was

(3) Structon Group, Wellington. imposed, when it would start to slide. Structural work commenced on site in 1977 and all bearings were placed during 1978. The project does therefore proceed the William Clayton building as the first using base isolating energy absorbing bearing pads.

Several problems encountered during design are of interest.

The consortium intended to use the bearing system under all its nuclear power stations built in seismic zones so that the plant on the nuclear island could then be to a common design (see clause 2.3.3. (a) of the paper). One of the major advantages anticipated using this approach was the reduction in design time required for each power station.

However, local seismic and site conditions did influence the duration and intensity of the design earthquake and affect the design of the nuclear island in a number of ways. For example the number of plastic (sliding) movements made is a factor in the design of isolation gaps and the services which cross the gap. It also affects the possibility of resonance of appendages. The most marked local effect was in the vertical acceleration input. The bearings are necessarily fairly stiff vertically and therefore there is no 'isolation' in the vertical direction. In fact with the site conditions at Koeberg (a very rigid base on bedrock) there was a marked buildup of energy in the plant from the vertical accelerations.

The designers were also asked to investigate the effect of surface waves on the plant. This had not previously been a requirement of the Atomic Energy Board for the commissioning of nuclear plants but the AEB felt that the bearings systems" behaviour may be altered or affected by simultaneous surface and body wave attack. The main problem here was to try and define the nature of the surface waves and to carry out a rational analysis.

After consultation with American researchers it was decided to use a finite wave train of pulses. It is now expected that all new nuclear power stations will be required to carry out a similar check.

It became obvious as the project proceeded that the economic advantage in using the bearings was debatable (in this case) because of the extremely strict safety requirements imposed. For example although tests had shown the bearings to have a coefficient of friction of between 0.16 and $0.2^{\circ}$ the analysis had to allow for a sliding range of 0.15 to 0.25 . Other factors include possible resonance of appendages (which could have been individually isolated in many cases) and the additional cost of the bearing system with its double basement slabs, increased excavation and only slightly reduced design content. It would seem advisable to carry out a very thorough cost/ benefit analysis of any future design, taking into account the problems of recommissioning a nuclear plant after a large earthquake.

Dr Ivan skinner (4) comments.

Preliminary calculations have suggested that correlation of vertical and horizontal ground motions could lead to substantial accumulated displacement of these non centering devices. addition the inability to accurately define the level

(4) Director, Physics and Engineering Laboratory, Gracefield, Lower Hutt. 
at which sliding begins is a major disadvantage.

The mechanical properties of other types of

devices is much more accurately known: for

example the coefficient of friction for the lead-

rubber shear damper can be specified within $5 \%$.

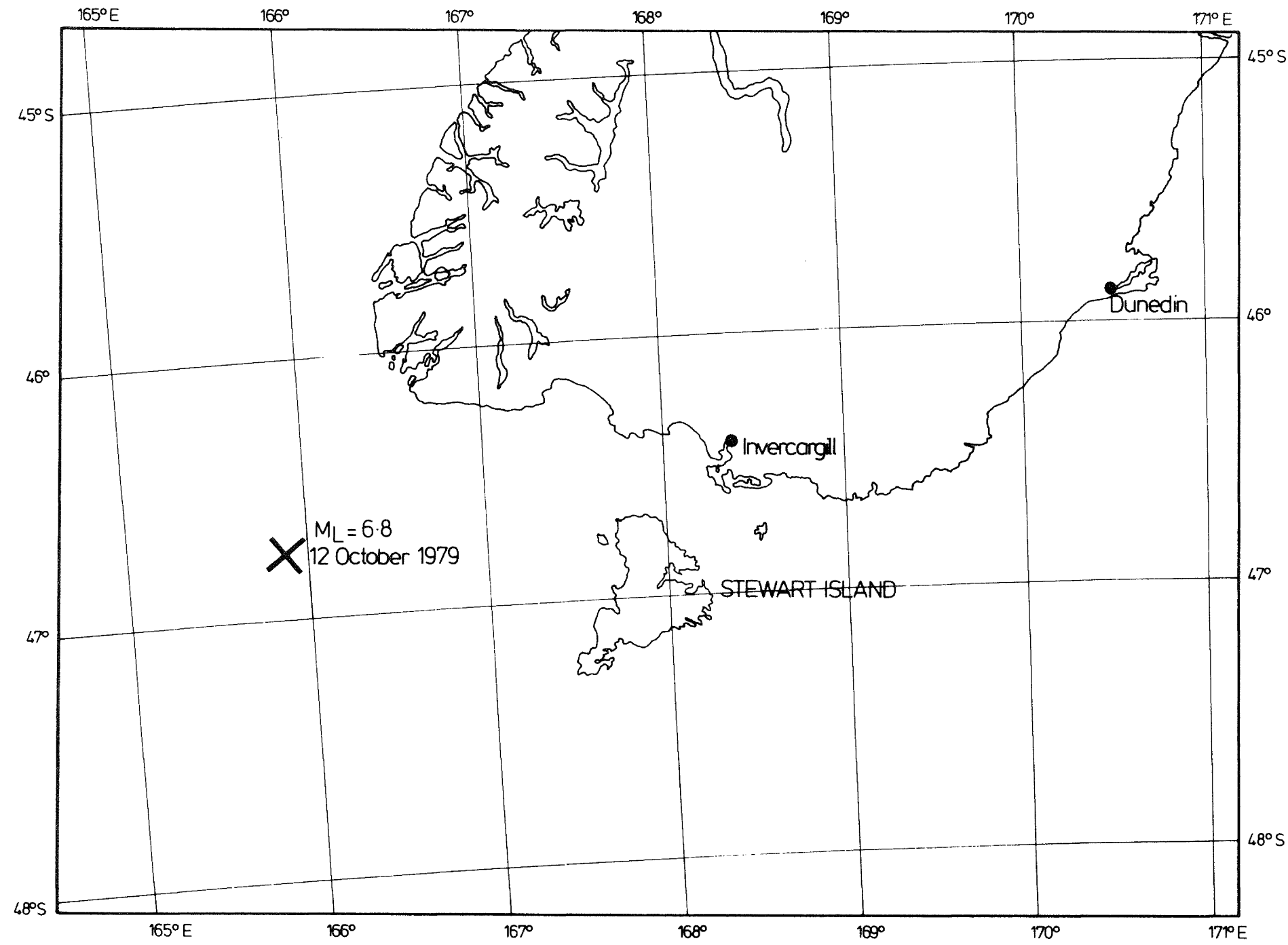

LOCATION OF SOUTHLAND EARTHOUAKE (SEE GENERAL INFORMATION SECTION) 